\title{
Corrigendum
}

\section{Bid-ding for mercy: twisted killer in action}

\author{
A Egle, D Asslaber, A Villunger and J Pinon-Hofbauer \\ Cell Death and Differentiation (2013) 20, 1284; doi:10.1038/cdd.2013.85; published online 28 June 2013
}

Correction to: Cell Death and Differentiation (2013) 20, 847-849; doi:10.1038/cdd.2013.40

The authors would like to make the following comment on their recently published editorial.

The views stated in our editorial were expressed under the assumption that all created genotypes had been generated under the same mixed background, which would allow some conclusions, given the cohort size presented. If, however, the mice were created without breeding C57BL/6 into the ATM-deficient control mice (as has been suggested in a commentary in this Journal), it may indeed be impossible to draw valid conclusions on the role of Bid in the context from the paper and an editorial review of content may be a futile exercise. Owing to the fact that we were not involved in the scientific review of this paper, we did, however, not have an opportunity to have the issues clarified. While we are thus aware of the potential shortcomings of the paper, we still elected to provide an editorial perspective on the topic raised. We chose to do this, as a number of previous lines of evidence supported a possible role of $\mathrm{BH} 3-$ only proteins (even Bid) in supporting tumorigenesis and we wanted to highlight the emerging data on this topic and open the field for discussion.

The authors would like to apologize for any inconvenience this may have caused. 